\title{
Predictors of Childhood Intractable Epilepsy- A Retrospective Study in A Tertiary Care Hospital
}

\author{
AKM MOINUDDIN ${ }^{1}$, MM RAHMAN $^{2}$, S AKHTER $^{3}$, CA KAWSER $^{4}$
}

\begin{abstract}
Objective: To study the predictors of intractable childhood epilepsy and to compare the predictors of outcome in early and late onset childhood epilepsy.

Design: Retrospective study.

Study place: Child Development and Neurology Unit in the Department of Paediatrics of Bangabandhu Sheikh Mujib Medical University (BSMMU).

Study period: January 2004 to December 2005.

Subjects: Children with epilepsy of 1 month to 15 years of age who attended the epilepsy clinic.

Results: The predictors of outcome of childhood epilepsy were analyzed. According to outcome there were two groups, well- controlled group (seizure free for more than 6 months) and intractable epilepsy (one or more seizures per month over a period of 6 months). The predictors of early and late onset childhood epilepsy were also compared. Total 73 cases were studied. Out of them 38 patients had early onset epilepsy (less than one year) and 35 had late onset epilepsy (more than one year). Median age of onset of early and late onset of childhood epilepsy group was 3.5 months and 60 months respectively. Male and female ratio was 1.53:1 and 0.94:1 in early and late onset group respectively. Major seizure type was tonic-clonic seizure in $57.9 \%$ and $77.1 \%$ patients of early and late onset group respectively. In this study, 27 (77.1\%) patients of late onset and 5(13.2\%) patients of early onset group achieved seizure remission. Independent predictors of intractable childhood epilepsy were finally found.

Conclusion: In this study symptomatic epilepsy, myoclonic seizure, initial high frequency of seizure, infantile spasm, neonatal seizures and birth asphyxia were significantly higher among early onset group than in late onset group. Early onset of seizure, myoclonic seizure, initial high frequency of seizure ( $\geq 1$ seizure/day), symptomatic etiology, neonatal seizure and microcephaly were found independent predictors of intractable epilepsy.
\end{abstract}

Key words: Early onset, late onset, intractable seizures.

\section{Introduction}

Worldwide fifty million people have epilepsy ${ }^{1}$. In Bangladesh it is estimated that there are at least 1.52 million people with epilepsy. In a community based survey at Dasher Kandi in Bangladesh, it was found that

1. Jonior Consultant, Raipur UHC, Lakshmipur

2. Professor, Paediatric Neurology, Department of Paediatrics, Bangabandhu Sheikh Mujib Medical University, Dhaka

3. Associate Professor, Paediatric Neurology, Department of Paediatrics, Bangabandhu Sheikh Mujib Medical University, Dhaka

4. Professor of Paediatrics, Bangabandhu Sheikh Mujib Medical University, Dhaka

Correspondence: Dr. AKM Moinuddin incidence of epilepsy was 2.54 per 1000 population². Worldwide overall prognosis of epilepsy is favorable, with $80 \%$ of patients being seizure free. However, $10-20 \%$ of patients develop medically intractable epilepsy ${ }^{3}$. The predictors of intractable epilepsy varies with age and are different among various geographic regions, and importantly, with the thoroughness of investigative technology used to un-reveal the etiology of epilepsy. Predictors of outcome of childhood epilepsy differs among early onset (onset before one year) and late onset (onset after one year) childhood epillepsy. There is a paucity of data regarding intractable epilepsy in Bangladesh, especially in children. Early identification of clinical predictors of intractable epilepsy according to age of 
onset of seizures would help in counseling patients and their families, selecting patients for intensive investigations and treatment with recently approved treatment as earliest and also to consider surgical and other non surgical treatments. This study was done to observe the clinical predictors of outcome of early and late onset childhood epilepsies and to observe the independent predictors of intractable childhood epilepsy.

\section{Materials and Methods}

It was a retrospective study. Duration of study was 2 years from January 2004 to December 2005. Study was done at Child Development and Neurology Unit in the Department of Paediatrics of Bangabandhu Sheikh Mujib Medical University. Inclusion criteria was epileptic children of 1 month to 15 years of age. Total 73 epileptic patients were enrolled in this study. Data of studied patients were collected purposfully on working days. They were divided into early onset group (onset of seizures before one year) and late onset group (onset of seizures after one year).

Thorough history of every aspect related to epilepsy was taken. Neuro-developmental and other relevant examinations were done in every patient. EEG was done in every patient. EEG was reported by paediatric neurologist. Imaging like CT scan / MRI, USG or Xray skull were done, where these were feasible and relevant. Blood sugar level, serum electrolytes, serum calcium and serum magnesium were estimated wherever required. Antiepileptic drugs were given to all epileptic children by the supervision of paediatric neurologist. Polytherapy was given when monotherapy failed. Serum drug level was measured in some of the patients, who required. All relevant information from history, clinical examination, investigation and followup visits were collected in pre-designed questionnaire.

Patients were divided again into two groups to find out the predictors of intractable epilepsy:

1. Well controlled group who responded to antiepileptic drug (Seizure free for more than 6 months).

2. Intractable group who did not respond to antiepileptic drug (AED) (One or more seizure per month over a period 6 months or more and who had experience trials of at least two different AEDs at optimum doses alone or in combination with adequate compliance).

Working definition followed in this study

1. Birth asphyxia: History of delayed cry after complete delivery or hospital record indicating birth asphyxia ${ }^{4}$.
2. Intractable epilepsy: Intractable epilepsy was considered in children who had one or more seizure per month over a period of 6 months or more and who had experienced trials of at least two different antiepileptic drugs alone or in combination at optimum doses with adequate compliance ${ }^{5}$.

3. Well controlled epilepsy: Children with epilepsy who had been seizure free for more than 6 months and who had been seizure free and never met the definition of intractable epilepsy ${ }^{5}$.

4. Partial seizure control : Defined as reduction of frequency of seizure but remained 1 or more seizure per month.

5. Complete seizure control: Defined as complete remission of seizure for two years.

6. An anti-epileptic drug was considered to have failed if it did not control seizure or if the medication was discontinued because of unacceptable side effects ${ }^{5}$.

7. A drug was not considered to have failed if serum level was sub-therapeutic or if there was documentation of poor compliance ${ }^{5}$.

8. In this study seizures were classified using the International League Against Epilepsy (ILAE) classification of epileptic seizure. Epilepsy and epileptic syndrome were classified by ILAE classification $1989^{6}$.

10. Microcephaly: Head circumference more than three standard deviation below the mean for age and sex 5,7 .

11. Status epilepticus was defined as a prolonged seizure of more than 30 minutes duration or a series of seizure occurring over a period of 30 minutes or more, during which time the child had never fully regained consciousness ${ }^{7}$.

12. Idiopathic epilepsy: The cause was unknown and there was no suggestion of an underlying cause other than a possible hereditary predisposition ${ }^{8}$.

13. Cryptogenic (Probably symptomatic) epilepsy: The cause was unknown but an underlying cause was suspected ${ }^{8}$.

14. Symptomatic (Remote symptomatic): The epilepsy occurred as a consequence of a known disorder of the brain ${ }^{8}$.

Data were processed and analysed by using soft-ware SPSS (Statistical Package for Social Sciences) version 11.5. The test statistics used to analysed the data were descriptive statistics, Chi-squared $\left(\chi^{2}\right)$ Test, Fisher's Exact Probability Test and Odds Ratio. The level of significance was 0.05 and $p<0.05$ was 
considered significant. Finally, all the variables who showed significant association with outcome were entered into logistic regression model to determine independent predictors of intractable epilepsy.

\section{Results}

Seventy three patients were analyzed. Out of them 38 patients had early onset epilepsy and the rest 35 had late onset epilepsy. Fifty percent of the early onset group had their first onset of seizure within 3 months, followed by $31.6 \%$ cases who had onset in between 4-6 months. The median age of onset was observed to be 3.5 months and the lowest and highest age of onsets were 1 and 12 months respectively. It is remarkable that in more than $80 \%$ cases of early onset group seizure appeared in the first 6 months (Fig.-1).

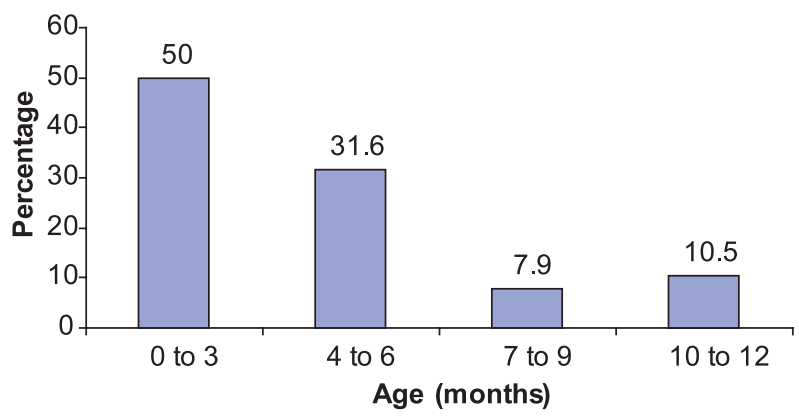

Fig.-1: Early onset group by age of onset of seizure $(n=38)$

Forty percent of the late onset group experienced their first seizure between 37-60 months. However there was wide spread distribution in different age groups. The median age of onset was found to be 60 months, while the lowest and highest ages of onset were 14 months and 168 months respectively (Fig.-2).

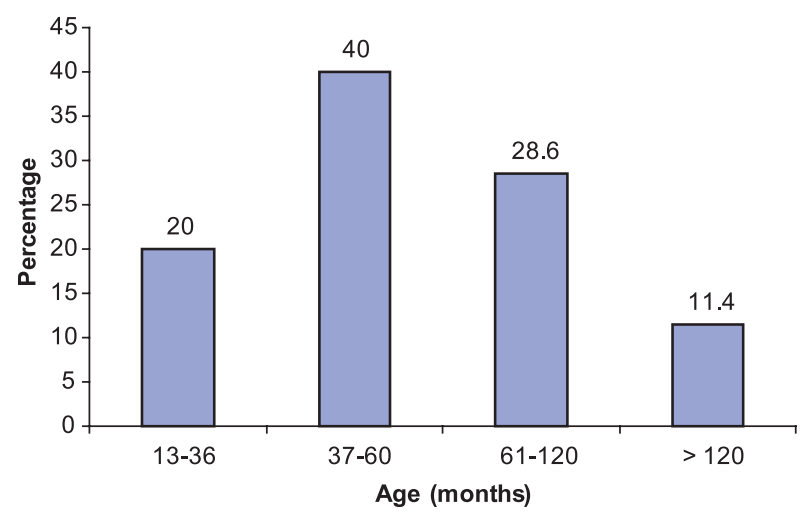

Fig.-2: Late onset group by age of onset seizure $(n=35)$
In early onset group 60.5\% were males and 39.5\% were females, while in late onset group males and females were almost equally distributed (48.6\% and $51.4 \%$ respectively). No significant statistical difference was observed between early and late onset groups with respect to sex $(p=0.305)$ (Table-I).

Table-I

Distribution of sex in early and late onset of seizure groups ( $n=73)$

\begin{tabular}{lccc}
\hline Sex & \multicolumn{2}{c}{ Group } & p-value \\
\cline { 2 - 3 } & Early onset & Late onset & \\
& $(n=38)$ & $(n=35)$ & \\
& No (\%) & No (\%) & \\
\hline Male & $23(60.5)$ & $17(48.6)$ & $0.305^{N S}$ \\
Female & $15(39.5)$ & $18(51.4)$ & \\
\hline
\end{tabular}

\#Chi-squared Test $\left(\chi^{2}\right)$ was conducted to compare the distribution of sex between groups; level of significance was 0.05 ; NS= Not significant

Predominant initial seizure type in early onset group was tonic-clonic in $57.9 \%$ followed by myoclonic seizure in $39.5 \%$ and clonic type in $2.6 \%$. In the late onset group tonic-clonic was higher (77.1\%) than their early onset counterpart, while the myoclonic seizure type was staggeringly low (5.7\% only). The absence type and mixed type were found only in the late onset group. The myoclonic seizure was much higher in early onset group compared to late onset (39.5\% vs. 5.7\%) (Fig.-3).

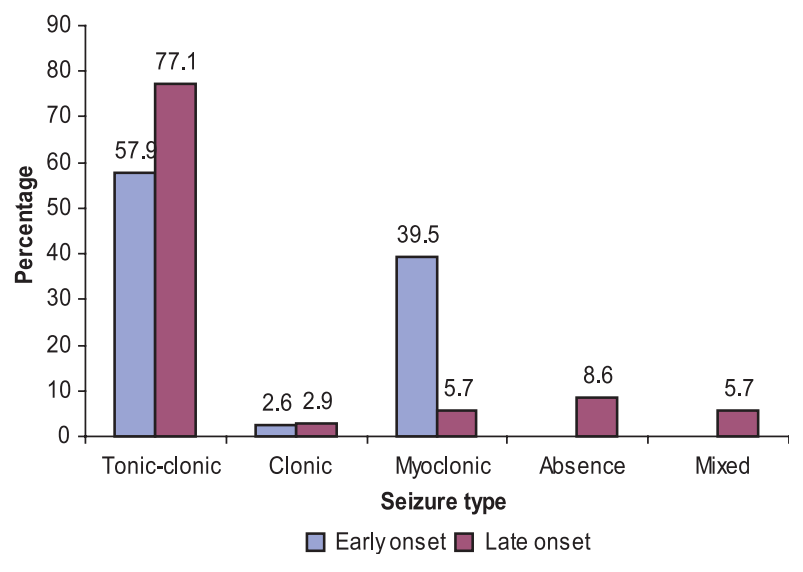

Fig.-3: Comparison of initial seizure type between early \& late onset of seizure group $(n=73)$ 
Events of symptomatic epilepsy, myoclonic seizure, initial frequency of seizure (one or more seizure/day), infantile spasm, neonatal seizure and birth asphyxia were significantly higher among early onset group than those in late onset group $(92.1 \%$ vs. $25.7 \%, p<0.001$; $39.5 \%$ vs. $5.7 \%, p<0.01 ; 71.1 \%$ vs. $20 \%, p<0.001$; $21.1 \%$ vs. $0 \%, p<0.05 ; 34.2 \%$ vs. $2.9 \%, p<0.005$ and $55.3 \%$ vs. $8.6 \%, p<0.001$ respectively). More than one-third $(36.8 \%)$ of the early onset had microcephaly compared to none of the late onset group $(p<0.001)$. However, the groups were found to be almost identical in terms of severe jaundice, status epilepticus, febrile seizure and family history of epilepsy ( $p>0.05$ ) (Table-II). More than $80 \%$ of the early onset and $77 \%$ of the late onset groups had EEG abnormality. The groups were found to be statistically homogeneous in respect to EEG abnormality $(p>0.05)$ (Fig.- 4).

\section{Table-II}

Comparison of preditors between early and late onset of seizure groups $(n=73)$

\begin{tabular}{|c|c|c|c|}
\hline \multirow[t]{2}{*}{ Predictors } & \multicolumn{2}{|c|}{ Group } & \multirow{2}{*}{$\begin{array}{c}\mathrm{p} \\
\text { value }\end{array}$} \\
\hline & $\begin{array}{l}\text { Early } \\
\text { No (\%) }\end{array}$ & $\begin{array}{l}\text { Late } \\
\text { No }(\%)\end{array}$ & \\
\hline Symptomatic epilepsy & $35(92.1)$ & $9(25.7)$ & $<0.001^{\star \star}$ \\
\hline Myoclonic seizure & $15(39.5)$ & $2(5.7)$ & $0.001^{*}$ \\
\hline $\begin{array}{l}\text { Initial frequency of seizure } \\
(\geq 1 / \text { day })\end{array}$ & $27(71.1)$ & $7(20.0)$ & $<0.001^{\star \star}$ \\
\hline Infantile spasm ${ }^{\#}$ & $8(21.1)$ & 00 & $0.004^{*}$ \\
\hline Neonatal seizure ${ }^{\#}$ & $13(34.2)$ & $1(2.9)$ & $0.002^{*}$ \\
\hline Birth asphyxia ${ }^{\#}$ & $21(55.3)$ & $3(8.6)$ & $<0.001^{* *}$ \\
\hline Severe jaundice & $3(7.9)$ & $1(2.9)$ & $0.339^{N S}$ \\
\hline Status epilepticus ${ }^{\#}$ & $1(2.6)$ & $1(2.9)$ & $0.732 \mathrm{NS}$ \\
\hline Febrile seizure & $6(15.8)$ & $8(22.9)$ & $0.444 \mathrm{NS}$ \\
\hline Family history epilepsy ${ }^{\#}$ & $3(7.9)$ & $1(2.9)$ & $0.339 \mathrm{NS}$ \\
\hline Microcephaly\# & $14(36.8)$ & 00 & $<0.001^{* *}$ \\
\hline
\end{tabular}

II Chi-squared Test $\left(\chi^{2}\right)$ was conducted to compare the data between groups;

\# Fisher's Exact Test was done to analyse the data; * $p$ $<0.05,{ }^{* *} p<0.001$ and NS= Not significant

The comparative response between groups after $1^{\text {st }}$ AED (antiepileptic drugs) reveals that nearly two-third $(65.7 \%)$ of the late onset group was seizure-free after $1^{\text {st }} A E D$, compared to only $1(2.6 \%)$ of the early onset

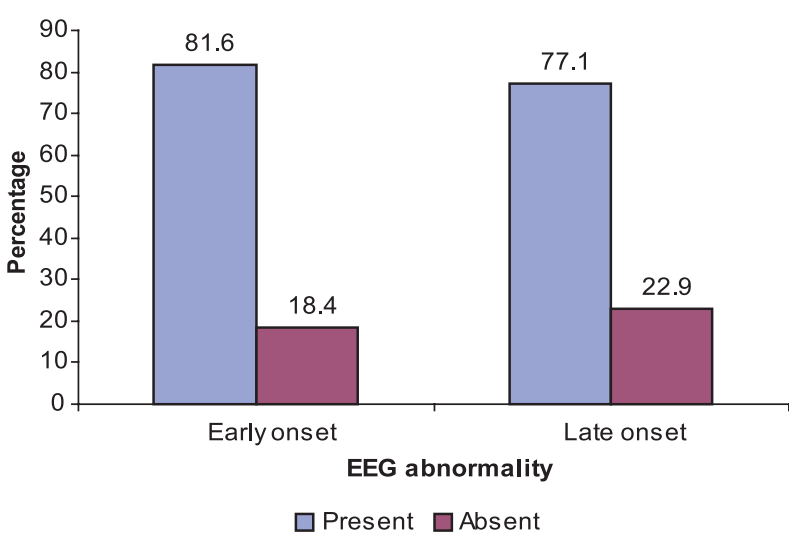

Fig.-4: Comparison of EEG abnormality between early $\&$ late onset of seizure groups ( $n=73$ )

group, indicating a significantly unfavourable response of early onset seizure $(p<0.001)$ (Table-III).

\section{Table-III}

Comparison of outcome between early \& late onset of seizure groups after $1^{\text {st }} A E D(n=73)$

\begin{tabular}{|c|c|c|c|}
\hline \multirow[b]{2}{*}{ Outcome } & \multicolumn{2}{|c|}{ Group } & $p$ \\
\hline & $\begin{array}{c}\text { Early onset } \\
\text { No (\%) }\end{array}$ & $\begin{array}{c}\text { Late onset } \\
\text { No (\%) }\end{array}$ & value* \\
\hline Seizure-free & $1(2.6)$ & $23(65.7)$ & $<0.001$ \\
\hline Not seizure-free & $37(97.4)$ & $12(34.3)$ & \\
\hline
\end{tabular}

${ }^{*}$ Chi-squared Test $\left(\chi^{2}\right)$ was employed to analyse the data

Evaluation of the response of 37 early onset and 12 late onset (who did not respond after $1^{\text {st }} \mathrm{AED}$ ) after giving $2^{\text {nd }} A E D$ showed that out of 37 early onset cases only $4(10.8 \%)$ cases became seizure-free leaving $33(89.2 \%)$ with continuing seizure. In contrast, 4 (33.3\%) of the remaining 12 late onset cases were seizure-free leaving $8(66.7 \%)$ to continue as before. The proportion of unfavourable response among early onset cases was observed to be much higher than that of late onset cases even after treatment with $2^{\text {nd }}$ AED $(p<0.001)$ (Table-IV).

\section{Table-IV}

Comparison of response between early \& late onset of seizure groups after $2^{\text {nd }} A E D(n=49)$

\begin{tabular}{|c|c|c|c|}
\hline \multirow[t]{2}{*}{ Outcome } & \multicolumn{2}{|c|}{ Group } & \multirow{2}{*}{$\begin{array}{c}\mathrm{p}- \\
\text { value }^{\star}\end{array}$} \\
\hline & $\begin{array}{c}\text { Early onset } \\
(\mathrm{n}=37) \\
\mathrm{No}(\%)\end{array}$ & $\begin{array}{c}\text { Late onset } \\
(n=12) \\
\text { No }(\%)\end{array}$ & \\
\hline Seizure-free & $4(10.8)$ & $4(33.3)$ & $<0.001$ \\
\hline Not seizure-free & 33 (89.2) & $8(66.7)$ & \\
\hline
\end{tabular}

*Chi-squared Test $\left(\chi^{2}\right)$ was conducted to analyse the data 
Majority of the early onset cases (86.8\%) exhibited unfavourable outcome or intractability, whereas majority of the late onset cases (77.1\%) demonstrated favourable outcome or complete remission after treatment with antiepileptic drugs $(p<0.001)$. The risk ratio shows that likelihood of developing unfavourable outcome in early onset group was 22-fold higher (10.04-51.01) than that in late onset group (Table-V).

It was observed that $15(88.2 \%)$ of the myoclonic seizure had unfavourable outcome compared to 26(46.4\%) for the other seizure type and the risk of developing unfavourable outcome was more than 8 times higher $(95 \% \mathrm{Cl}=3.98-18.93)$ in myoclonic seizure than that of other types of seizure. Likewise the chance developing unfavourable outcome was found to be more than 13fold higher $(95 \% \mathrm{Cl}=6.65-29.8)$ in patients who had 1 or more seizure/day than those who had $<1$ seizure/day. The likelihood of developing unfavourable outcome was found to be more than 8 times higher $(95 \% \mathrm{Cl}=4.75$ $15.57)$ in patients with symptomatic epilepsy than those with idiopathic epilepsy $(p<0.001)$. Analysis also showed that $12(85.7 \%)$ of neonatal seizure, $21(87.5 \%)$ of birth asphyxia and 13 (92.9\%) of microcephaly had unfavourable outcome and the risk of developing such outcomes were found to be 5.9 (2.86-12.28), 9.6 (2.5220.84) and 14.9 (5.96-39.2) times greater in neonatal seizure, asphyxiated baby and microcephaly than those who did not have these conditions. On the other hand, sex, status epilepticus and febrile convulsion could not predict any outcome $(p>0.05$ and OR 1 or $<1)$. The risk of unfavourable outcome due to infantile spasm could not be computed as the favourable outcome with this condition was 0 (zero). The risk of developing unfavourable outcome in patients with EEG abnormality was calculated to be 3-fold higher $(95 \% \mathrm{Cl}=1.78-6.18)$ than those without EEG abnormality $(p<0.05)($ Table-VI).

Table-V

Comparison of final outcome between early \& late onset of seizure groups ( $n=73)$

\begin{tabular}{|c|c|c|c|c|}
\hline \multirow[b]{2}{*}{ Outcome } & \multicolumn{2}{|c|}{ Group } & \multirow{2}{*}{$\begin{array}{c}\text { OR } \\
(95 \% \mathrm{Cl})\end{array}$} & \multirow{2}{*}{$\begin{array}{c}\mathrm{p} \\
\text { value* }^{*}\end{array}$} \\
\hline & $\begin{array}{c}\text { Early onset } \\
\text { No (\%) }\end{array}$ & $\begin{array}{c}\text { Late onset } \\
\text { No (\%) }\end{array}$ & & \\
\hline Unfavourable/Intractable & $33(86.8)$ & $8(22.9)$ & 22.4 & $<0.001$ \\
\hline Favourable /Complete remission & $5(13.2)$ & 27 (77.1) & $(10.04-51.01)$ & \\
\hline
\end{tabular}

${ }^{*}$ Chi-squared Test $\left(\chi^{2}\right)$ was conducted to compare the distribution of outcome between groups

Table-VI

Predictors of unfavorable outcome (bivariate analysis)

\begin{tabular}{|c|c|c|c|c|}
\hline \multirow[b]{2}{*}{ Predictors } & \multicolumn{2}{|c|}{ Outcome* } & \multirow{2}{*}{$\begin{array}{c}\text { OR } \\
(95 \% \mathrm{Cl})\end{array}$} & \multirow{2}{*}{$\begin{array}{c}\mathrm{p} \\
\text { value }\end{array}$} \\
\hline & $\begin{array}{l}\text { Intractable } \\
(n=41) n / n\end{array}$ & $\begin{array}{l}\text { Well controlled } \\
(n=32) n / n\end{array}$ & & \\
\hline$\overline{\text { Sex (male/female) })^{\pi}}$ & $23 / 18$ & $17 / 15$ & $1.08(0.60-1.97)$ & $0.800^{\mathrm{NS}}$ \\
\hline Initial Seizure type (myoclonic/others) & $15 / 26$ & $2 / 30$ & $8.6(3.98-18.93)$ & $0.002^{*}$ \\
\hline $\begin{array}{l}\text { Initial seizure frequency } \\
(\geq 1 \text { per day } /<1 \text { per day })^{\pi}\end{array}$ & $29 / 12$ & $5 / 27$ & $13.8(6.65-29.8)$ & $<0.001^{\star \star}$ \\
\hline $\begin{array}{l}\text { Etiologic classification } \\
\text { (symptomatic/idiopathic) }\end{array}$ & $38 / 3$ & $6 / 26$ & $8.6(4.7-15.5)$ & $<0.001^{\star \star}$ \\
\hline Infantile spasm (Yes/No)\# & $8 / 33$ & $0 / 32$ & Undefined & $0.007^{*}$ \\
\hline Neonatal seizure (Yes/No) & $12 / 29$ & $2 / 30$ & $5.9(2.86-12.28)$ & $0.013^{*}$ \\
\hline Birth asphyxia (Yes/No $)^{\pi}$ & $21 / 20$ & $3 / 29$ & $9.6(2.52-20.84)$ & $<0.001^{\star *}$ \\
\hline Family history of epilepsy (Yes/No) & $3 / 38$ & $1 / 31$ & $2.4(1.29-4.68)$ & $0.409^{N S}$ \\
\hline Status epilepticus(Yes/No) & $1 / 40$ & $1 / 31$ & $0.75(0.42-1.37)$ & $0.688^{N S}$ \\
\hline Febrile seizure (Yes/No $)^{\pi}$ & $6 / 35$ & $6 / 24$ & $0.52(0.29-0.96)$ & $0.264^{N S}$ \\
\hline Microcephaly (Yes/No) $)^{\pi}$ & $13 / 28$ & $1 / 31$ & $14.9(5.96-39.2)$ & $0.002^{*}$ \\
\hline EEG abnormality (Yes/No) ${ }^{\pi}$ & $36 / 5$ & $22 / 10$ & $3.31(1.78-6.18)$ & $0.046^{*}$ \\
\hline
\end{tabular}

* Outcome statistics are expressed as No (\%); ๆ Chi-squared Test $\left(\chi^{2}\right)$ was conducted to compare the distribution of events between groups; \# Fisher's Exact Test was done analyse the data; ${ }^{*} p<0.05,{ }^{* *} p<0.001$ and NS $=$ Not significant 
Table-VII

Logistic regression analysis for predictors of unfavourable outcome

\begin{tabular}{|c|c|c|c|c|c|}
\hline \multirow{3}{*}{ Predictors } & \multicolumn{3}{|c|}{ Bivariate analysis } & \multirow{2}{*}{\multicolumn{2}{|c|}{$\begin{array}{l}\text { Multivariate analysis } \\
\text { Hosmer and }\end{array}$}} \\
\hline & Outco & & $p$ & & \\
\hline & $\begin{array}{c}\text { Unfavourable } \\
\text { No }\end{array}$ & $\begin{array}{l}\text { Favourable } \\
\text { No }\end{array}$ & value & $\begin{array}{l}\text { Lemeshow } \\
\text { Test ( } p \text { value) }\end{array}$ & $\begin{array}{c}\text { Odds Ratio } \\
(95 \% \mathrm{Cl})\end{array}$ \\
\hline Early onset(at 1year or earlier) & 33 & 5 & $<0.001$ & & $\begin{array}{c}3.5^{\star \star} \\
(0.43-28.02)\end{array}$ \\
\hline Initial seizure type(myoclonic) & 15 & 2 & 0.002 & & $\begin{array}{c}1.6^{\star \star} \\
(0.12-21.44)\end{array}$ \\
\hline Initial seizure frequency( $\geq 1$ per day) & 29 & 5 & $<0.001$ & & $\begin{array}{c}1.5^{\star \star} \\
(0.79-2.77)\end{array}$ \\
\hline Etiologic classification (symptomatic) & 38 & 6 & $<0.001$ & & $\begin{array}{c}3.3^{* *} \\
(1.26-8.60)\end{array}$ \\
\hline Infantile spasm (present) & 8 & 0 & 0.007 & 0.643 & Not computed* \\
\hline Neonatal seizure (present) & 12 & 2 & 0.013 & & $\begin{array}{c}1.5^{\star \star} \\
(0.07-18.72)\end{array}$ \\
\hline Birth asphyxia (present) & 21 & 3 & $<0.001$ & & $\begin{array}{c}0.27 \\
(.03-2.43)\end{array}$ \\
\hline Microcephaly (present) & 13 & 1 & 0.002 & & $\begin{array}{c}1.02^{\star \star} \\
(0.04-21.69)\end{array}$ \\
\hline EEG abnormality (present) & 36 & 22 & 0.046 & & $\begin{array}{c}0.35 \\
(0.04-2.92)\end{array}$ \\
\hline
\end{tabular}

* Goodness-of-fit test did not allow infantile spasm to be entered into the model because at least 1 cell had expected value $<1$; ** Significant predictors

Logistic regression analysis of odds ratios, for characteristics of the children, showed the predictors of the unfavourable outcome. The variables revealed to be significantly associated with unfavourable outcome by bivariate analyses were all entered into the model directly. The insignificant Chi-square produced by Hosmer and Remeshow goodness-of-fit test shows that the model is a good fit model. Out of 9 variables entered into the model, infantile spasm was deleted by Hosmer and Remeshow goodnessof-fit test. Of the remaining 8 variables, onset of seizure at age 1 year or earlier, myclonic seizure, initial frequency of seizure 1 or more per day, symptomatic etiology, neonatal seizure and microcephaly were found to be the independent predictors of unfavorable outcome with ORs being 3.5, $1.6,1.5,3.3,1.5$ and 1.02 respectively (Table-VII).

\section{Discussion}

Unfavourable outcome or intractability is a burning concern for both patients and personnel dealing with epilepsy. This study was done to search the factors that were associated with unfavourable outcome or intractability. Early identification of these factors would help in planning early intervention. Predictors were studied in early and late onset groups. It was observed that $50 \%$ and $31.6 \%$ patients of early and late onset group had onset of seizure within 3 months and 4 to 6 months respectively. This might be due to the fact that epileptic encephalopathies present early in life ${ }^{3}$. In early onset group, males (60.5\%) were higher than females (39.5\%), but in late onset group, it was equally distributed. Most epidemiological studies reported a slightly higher incidence of epilepsy in boys than girls. Another report showed that epilepsy was 2.4 times more in males than in females ${ }^{9}$. Exact cause of this male preponderance in childhood epilepsy is not known. It can be that boys get preference in the family in seeking health-care.

It was observed that $86.8 \%$ of early onset group compared to $22.9 \%$ of late onset had developed intractable epilepsy. Early age of onset was found as an independent predictor of unfavourable outcome or intractable epilepsy $(P<0.001)$. Chawla et $\mathrm{al}^{5}$ found $66 \%$ of intractable group compared to $04 \%$ of well 
controlled epilepsy had early onset of seizure. Berg et al ${ }^{10}$ found $52.6 \%$ of intractable cases compared to only $9.4 \%$ of well controlled epilepsy had early onset of seizure. In another study at Okayama University it was found that $53 \%$ patients of early onset epilepsy had unfavourable outcome $(P<0.005)^{11}$. Hauser et al ${ }^{9}$ also found it as a predictor of unfavourable outcome. Tae-sung and Holmes also found it as an independent predictor of intractable epilepsy (OR $=0.86$ per year, $95 \% \mathrm{Cl} 0.75,0.97)$. In that study mean age of 144 intractable epilepsy cases were 2.9 years and that of 39 well-controlled cases were 5.2 years ${ }^{12}$.

In a recent prospective study of prognosis of seizure occurring in the first year of life, Datta and Wirrell found that $38 \%$ of the 40 patients with an onset of seizure in the first year of life had uncontrolled seizures at follow-up ${ }^{13}$. Epilepsy due to structural malformation like, microcephaly and macrocephaly, tuberous sclerosis, neuronal migration disorders like lissencephally, pachygyria, etc. present in early life. These epilepsies are difficult to control. Epilepsy associated with various congenital errors of metabolism present early in the life are difficult to control. Severe brain damage caused by severe perinatal insult manifest early in the life. A significant number of which also become intractable ${ }^{9-13}$. Early onset group had significant association with symptomatic etiology, infantile spasm, myoclonic seizure, neonatal seizure, microcephaly, birth asphyxia and high initial frequency of seizure. Berg et $\mathrm{al}^{10}$ found infantile spasm, remote symptomatic seizure and neonatal seizure was significantly associated with early onset epilepsy. Early age of onset was found as a predictor of intractability in many studies, but its association with other predictors was not searched much. In this respect this study was designed to focus on early age of onset and its association with many other events which has got predictive influence on outcome of epilepsy. Reducing neonatal seizure and perinatal asphyxia by providing proper perinatal care, prevalence of early onset seizure and intractable epilepsy can be reduced.

It was revealed that $23(65.7 \%)$ cases of late onset group and 1 (2.6\%) cases of early onset group had remission after first drug. In case of second drug, $4(33.3 \%)$ of the remaining cases of late onset group and $4(10.8 \%)$ of early onset group had remission, who had not responded to first drug. Datta and Wirrel also found that on multiple drug trials among responders, response to first antiepileptic drug was significant ${ }^{13}$. Camfield found response to initial drug therapy as a predictor of remission. Though the remission rate in this study was poor in case of second anti-epileptic drug compared to that of first, but the total percentage of response was increased ${ }^{14}$.

This study showed that $86.4 \%$ cases of symptomatic epilepsy developed intractability. It was found as an independent predictor of unfavourable outcome $(P<0.001)$. Chawla et $\mathrm{al}^{5}$ found $80 \%$ of intractable group compared to $2.8 \%$ of well-controlled group had symptomatic etiology $(\mathrm{P}<0.001)$. Hypoxic-Ischaemic damage of the brain due to perinatal asphyxia and cerebral palsy were the main causes of symptomatic epilepsy in that study. Chawla et al. also found perinatal asphyxia was the main cause of symptomatic epilepsy in intractable group and neurocysticercosis was the main cause of symptomatic epilepsy in wellcontrolled group of their study. Berg et $\mathrm{al}^{15}$ found only $1.7 \%$ of idiopathic epilepsy compared to $12.5 \%$ of symptomatic group developed intractability, which was statistically significant. Chawla et $\mathrm{al}^{5}$ found among the intractable group $80 \%$ had symptomatic etiology compared to $12.5 \%$ that was found in the study of Berg et $\mathrm{al}^{15}$. This difference was due to the fact that study of Chawla et al ${ }^{5}$ was retrospective with biased samples of 100 cases. On the other hand Berg et al $^{15}$ conducted a prospective study with 613 cases. So, the findings of Berg et $\mathrm{al}^{15}$ were more acceptable. Tae-sung and Holmes found symptomatic etiology in $55.6 \%$ cases of intractable epilepsy compared to $20.5 \%$ of well-controlled epilepsy cases $(P<0.001)^{12}$. Ohtsuka, Yoshinaga and Kobayshi found $52 \%$ of the cases with symptomatic etiology developed refractory seizure, which was statistically significant $(P<0.005)^{11}$.

In this study initial high frequency of seizure ( $\geq 1$ per day) was found as an independent predictor of intractable epilepsy. Similar results were found in other studies $5,9,12,15$. Sillanpaa found $87.2 \%$ of patient having refractory epilepsy had high initial seizure frequency ${ }^{3}$. Chawla et $\mathrm{al}^{5}$ found that $76 \%$ of intractable group compared to $22 \%$ of well-controlled epilepsy had daily seizure $(P<0.001)$. Malignant syndromes of epilepsy which are difficult to control present with high frequency of seizure. But frequent seizure itself further damages the developing brain which already has got pathology of seizure. It might also be remembered that less frequent status can be more devastating than 
frequent short episodes of seizure ${ }^{16}$. Berg et $\mathrm{al}^{15}$ showed that, out of 99 cases having less than one seizure per month, only 1 case developed intractable epilepsy ( $p<0.001$ ). Tae-sung and Holmes found daily seizure in $50.7 \%$ cases of intractable epilepsy compared to $25.6 \%$ of well-controlled epilepsy $(p<0.001)^{12}$.

Considering the seizure type, tonic-clonic seizure was the commonest type in our study. In early onset group it was $57.9 \%$ and in late onset group it was $77.1 \%$. Others also found it as the commonest variety (39$44 \%)$. It might be due to the fact that significantly higher number of idiopathic generalized tonic-clonic epilepsy present at later age $\mathrm{e}^{3-5}$. Myoclonic seizure was remarkably higher (39.5\% vs $5.7 \%$ ) in early onset group compaired to late onset. Various malignant syndromes like infantile spasm, early myoclonic encephalopathy, severe myoclonic epilepsy in infancy etc. present very early in the life. This might be one of the reasons of getting higher myoclonic seizure in early onset group ${ }^{3,4}$. Myoclonic seizures were also significantly associated with unfavourable outcome. It was found as an independent predictor of unfavourable outcome. Chawla et al $\left.\right|^{5}$ found $32 \%$ of intractable cases compared to $4 \%$ of well-controlled group had myoclonic seizure $(P<0.001)$. Tae-sung and Holmes found $32.6 \%$ of intractable group compared to $10.3 \%$ of well-controlled group had myoclonic seizure which was statistically significant ${ }^{12}$. Berg et $\mathrm{al}^{10}$ found myoclonic/atonic seizure in $21 \%$ of intractable cases compared to $4.2 \%$ cases of wellcontrolled epilepsy ( $p=0.015)$. This might be due to malignant syndromes in infancy present with myoclonic seizure, which are difficult to control.

Infantile spasm was found significantly associated with intractibility in this study $(\mathrm{P}=0.007)$. Berg et $\mathrm{al}^{10}$ found infantile spasm in $19.7 \%$ cases of intractable epilepsy compared to $1 \%$ cases of well-controlled group $(P=0.003)$. It is a well-known malignant syndrome and difficult to control.

In this study $85.7 \%$ cases who had neonatal seizure was intractable epilepsy. It was found as an independent predictor of intractable epilepsy. Berg et $\mathrm{al}^{10}$ in their study showed that $17.1 \%$ of intractable patients compared to only $5.2 \%$ of well-controlled patients had neonatal seizure $(P=0.01)$. Chawla et $\mathrm{al}^{5}$ found $30 \%$ of intractable patients compared to only $2 \%$ of well-controlled epileptic patients had neonatal seizure $(P<0.001)$. In another study at Okayama
University it was found that 5 (100\%) patients of their series who had neonatal seizure developed refractory epilepsy and it was statistically significant ${ }^{11}$. When the developmental abnormality of brain are severe they present early and one of the presentations may be neonatal seizure. This is true for various inborn errors of metabolism too ${ }^{9-12}$.

Ninety three percent of patients with microcephaly in this study developed intractable epilepsy. It was found as an independent predictor of intractable epilepsy. Chawla et al ${ }^{5}$ found $58 \%$ of intractable group compared to $2 \%$ of well-controlled group had microcephaly $(P<0.001)$. Berg et $\mathrm{al}^{10}$. found $23.7 \%$ cases of intractable group compared to only $3.1 \%$ of wellcontrolled group had microcephaly $(\mathrm{P}<0.001)$.

Birth asphyxia is a concern for countries of this subcontinent, where antenatal and perinatal care is still poor. In this study $87.5 \%$ epileptic children with history of birth asphyxia subsequently developed intractable epilepsy. It was found significantly associated with intractable epilepsy $(P<0.001)$. Selina et $\mathrm{al}^{17}$ and Chawla et al ${ }^{5}$ found similar result. But in western countries with optimum perinatal care it was not found even as a risk factor of epilepsy.

They found history of convulsions in the mother, febrile seizures and head trauma as risk factors of epilepsy . But low birth weight, asphyxia or postmaturity were not found as risk factors ${ }^{18}$.

History of status epilepticus was not found as a predictor of unfavourable outcome or intractability. This finding is in contrast with the finding of Sillanpaa ${ }^{3}$. Ohtsuka, Yoshinaga and Kobayashi in their study found $29(69 \%)$ patients with history of status epilepticus became refractory cases $(p<0.005)^{11}$. But most of the other studies had not found it as a predictor $^{5,15}$. It has been seen that subsequent episodes of status epilepticus occurred at various times during the seizure disorder, generally after a pattern of intractability has been established ${ }^{16}$, which also suggests that status epilepticus is a marker rather than a cause of intractability ${ }^{19}$.

Family history of epilepsy had no significant association with unfavourable outcome $(P=0.409)$. Other studies also showed similar results $3,5,15$. Indeed positive family history are more commonly found in benign conditions like Idiopathic generalized tonicclonic epilepsy. On the other hand malignant syndromes like early myoclonic encephalopathy, 
severe myoclonic epilepsy of infancy etc., which also has got family history, but are less in incidence ${ }^{8}$. Epileptic children suffer from febrile convulsion relatively more. Some claimed that this might be due to their low seizure threshold ${ }^{10}$. Incidence of febrile seizure in general population is $3-4 \%^{7}$. In this study $19.17 \%$ of epileptic children had history of febrile seizure but it was not found as a predictor of unfavourable outcome. Other studies have shown similar results ${ }^{11,14,15}$.

Early and late onset groups were statistically homogenous in respect to EEG abnormality. EEG abnormality is significantly associated with unfavourable outcome $(P=0.046)$. Selina et $\mathrm{al}^{17}$ found similar result. Many benign syndromes like idiopathic generalized tonic-clonic epilepsy may present epileptiform discharges on EEG, absence seizure got generalized $3 \mathrm{~Hz}$ spike-wave discharges, rolandic epilepsy got temporal epileptiform discharges. On the other hand, malignant syndromes like epileptic encephalopathies got background slowing. Encephalitis and hypoxia-ischaemic encephalopathy may have burst suppression, infantile spasm presents hypsarrythmia on EEG. So, it is more precise to search for specific EEG finding as a predictor as done by western investigators. Berg et al. found focal EEG slowing as predictor ${ }^{15}$. Focal and diffuse spike and wave was also found as predictor ${ }^{11}$. Tae-sung and Holmes found diffuse slowing and focal spike and wave activity as predictor of unfavorable outcome ${ }^{12}$. On the other hand patients without high grade EEG background abnormality was found having favorable outcome ${ }^{20}$.

\section{Conclusion}

In this study symptomatic epilepsy, myoclonic seizure, initial high frequency of seizure, infantile spasm, neonatal seizures and birth asphyxia were significantly higher among early onset group than in late onset group. Early onset of seizure, myoclonic seizure, initial high frequency of seizure ( $>1$ seizure/ day), symptomatic etiology, neonatal seizure and microcephaly were found independent predictors of intractable epilepsy. As this study was not a prospective one, population based prospective studies with adequate number of cases representing the community are required.

\section{References}

1. Shorvon SD. The Epidemiology and Treatment of Chronic and Refractory Epilepsy. Epilepsia1996; 37 (Suppl. 2): S1-S3.

2. Chowdhury AKMN, Alam MN, Au SMK. Dasher kandi Project Studies. Bangladesh Med Res Council Bull 1981; 7: 22-39.

3. Sillanpaa M. Remission of Seizures and Predictors of Intractability in Long-term followup. Epilepsia 1993; 34: 930-36.

4. Suvanand S, Kapoor SK, Reddaiah VP, Singh U, Sundaram KR. Risk factors for cerebral palsy. Indian Pediatr 1997; 64: 677- 85.

5. Chawla S, Aneja S, Kashyap R, Mallika V. Etiology and Clinical Predictors of Intractable Epilepsy. Pediatric Neurology 2002; 27: 186-91.

6. Commission on Classification and Terminology of the International League Against Epilepsy. Proposal for revised classification of epilepsies and epileptic syndromes. Epilepsia 1989; 30: 389-99.

7. Johnston MV. Seizures in childhood. In: Behrman RE, Kliegman RM, Jenson HB, editors. Nelson Textbook of Pediatrics. 17th ed. Philadelphia: Saunders; 2004. P. 1993-2009.

8. Ferrie C, Martland T, Newton R. Neurology. In: McInntosh N, Helms JA, Smyth LR, editors. Forfer and Arneil's Textbook of Paediatrics. $6^{\text {th }}$ ed. London: Churchill Livingstone; 2004. P. 889-1056.

9. Hauser E, Freilinger M, Seidl R, Groh C. Prognosis of Childhood Epilepsy in Newly Referred Patients. Journal of Child Neurology 1996; 11: 201-04.

10. Berg AT, Levy SR, Novotry EJ, Shinnar S. Predictors of intractable epilepsy in childhood: A case control study. Epilepsia 1996; 37: 2430.

11. Ohtsuka Y, Yoshinaga H, Kobayashi K. Refractory childhood epilepsy and factors related to refractoriness. Epilepsia 2000; 41 (Suppl.9): S14-S17.

12. Tae-Sung K, Holmes GL. EEG and clinical predictors of medically intractable childhood epilepsy. Clinical Neurophysiology 1999; 110: 1245-51. 
13. Datta AN, Wirrell EC, Elaine C. Prognosis of Seizures Occuring in the First Year. Pediatric Neurology 2000; 22: 386-91.

14. Camfield C, Camfield P, Gordon K, Smith B, Dooley J. Outcome of childhood epilepsy: A population-based study with a simple predictive scoring system for those treated with medication. The Journal of Pediatrics 1993; 122: 861-68.

15. Berg AT, Shinnar S, Levy SR, Testa FM, SmithRapaport, Beckerman B. Early development of intractable epilepsy in children. Neurology 2001; 56: 1445-52.

16. Aicardi J. Diseases of the Nervous System in Childhood. $2^{\text {nd }}$ ed. London; Mac Keith Press; 1998.
17. Banu SH, Khan NZ, Hossain M, Nahan A, Parvin M, Rahman N, et al. Profile of childhood epilepsy in Bangladesh. Developmental Medicine and Child Neurology 2003; 45: 477-82.

18. Rocca WA, Sharbrough FW, Hauser WA, Annegers JF, Schoenberg BS. Risk factors for absence seizure: A population-based casecontrol study in Rochester, Minnesota. Neurology 1987; 37: 1309-14.

19. Maytal J, Shinnar S, Moshe SL, Alvarez LA. Low morbidity and mortality of status epilepticus in children. Pediatrics 1989; 83: 323-31.

20. Okume T, Kumashiro H. Natural History. Prognosis of Epilepsy: Report of a Multiinstitutional Study in Japan. Epilepsia 1981; 22: 35-53. 